\title{
O Psicólogo como Facilitador da Interação Familiar no Ambiente de Cuidados Intensivos Neonatais
}

The Psychologist as a facilitator of family interaction in neonatal intensive care unit

\section{Luciana Valansi}

Psicóloga pelo Instituto de Psicologia

da Universidade

Federal do Rio de Janeiro.

Denise Streit Morsch

Psicóloga da Clínica Perinatal Laranjeiras/RJ; Doutora em Saúde da

Criança e da Mulher pelo Instituto Fernandes Figueira/Fiocruz.

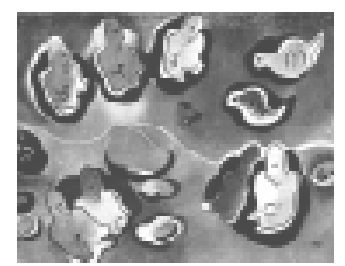

Resumo: Neste artigo, apresentaremos a atenção com o processo interativo entre o bebê e sua família como uma das prioridades do psicólogo numa unidade de tratamento intensivo neonatal. Inicialmente, iremos caracterizar o ambiente de uma UTI neonatal e, em seguida, discutir o momento evolutivo da família a partir das experiências ocorridas durante a gestação e daquelas provocadas pelo parto antecipado ou de risco. Compreendendo esses dois aspectos - o ambiente e o momento em que se encontram os diferentes personagens familiares - discutiremos as possibilidades de cuidados que o psicólogo pode oferecer, privilegiando a saúde através de vias facilitadoras da interação familiar.

Palavras-Chave: Cuidados intensivos neonatais, interação pais-bebê, Psicologia Hospitalar.

Abstract: In this article we present the care in the interactive process between the baby and his family as one of the priorities of the psychologist in a neonatal intensive care unit. First we will characterize the environment of a $\mathrm{NICU}$, and then discuss the family moment based on the experiences that happened during the pregnancy and the ones caused by a premature or risk labor. Comprehending these two aspects - the environment and the moment that the different family characters are going through - we will discuss some possibilities of the care that a psychologist can offer, providing health through the facilitation for the family interaction.

Key Words: Neonatal intensive care, parents-baby interaction, Hospital Psychology.

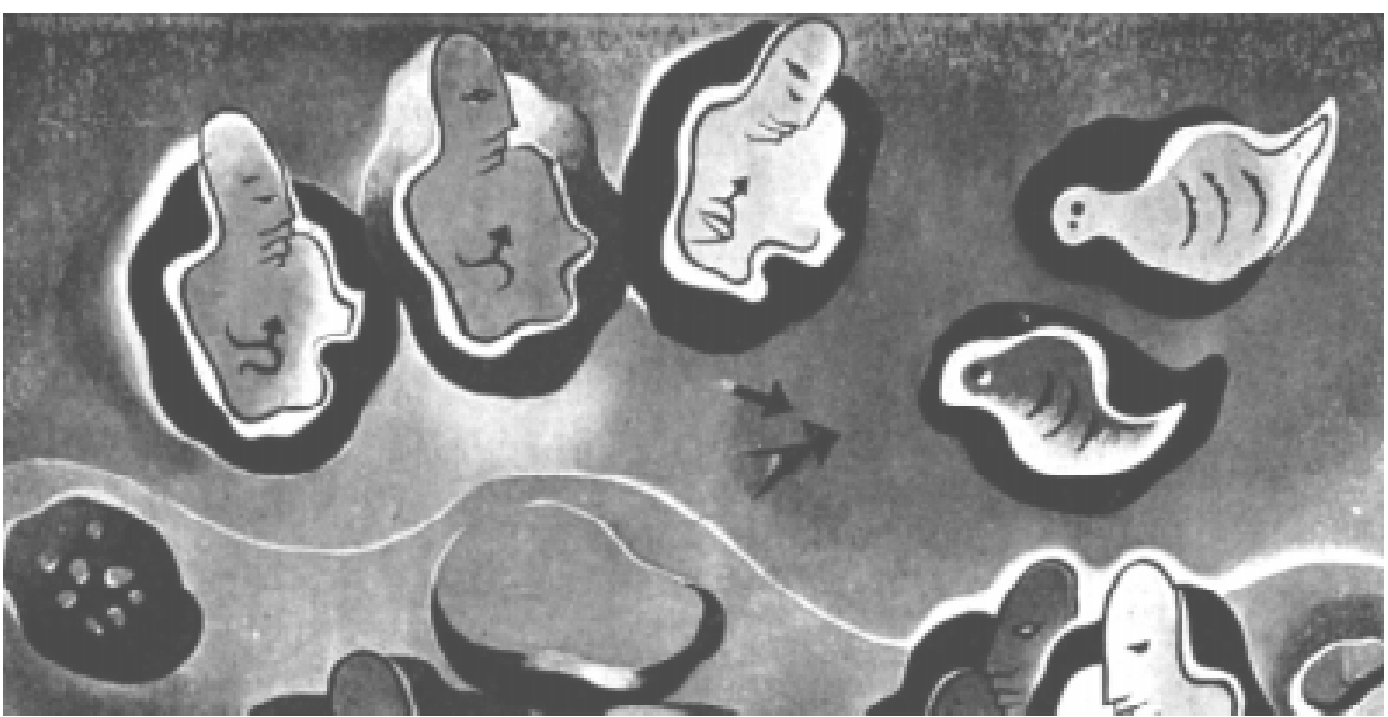

\section{A UTI Neonatal}

Segundo Klaus \& Kennell (1993), os eventos cruciais da vida, seja o desenvolvimento do apego (ao nascimento) ou o do desapego (a morte), têm sido retirados do lar e trazidos para dentro do hospital. Assim, as experiências afetivas que cercam esses eventos foram despojadas de suas tradições e dos sistemas de apoio formados durante séculos, que ajudavam as famílias nesses momentos de transição.
Em relação às crianças recém-nascidas, ressaltam os autores que o surgimento dos berçários ocorreu no início do século XX, em função do alto índice de morbidade e mortalidade dessa população. Foram, então, criadas técnicas rigorosas para isolar os pacientes considerados infectados daqueles não infectados. As visitas eram energicamente desestimuladas devido à crença de que seriam as responsáveis por carrearem infecção para dentro 
das paredes hospitalares. Assim, a preocupação em proteger os pacientes das doenças contagiosas levou ao que hoje consideramos medidas bizarras de isolamento e de separação. Nos maiores hospitais pediátricos, as visitas não duravam mais que 30 a 60 minutos e, em alguns, havia inclusive proibição de entrada de familiares. ${ }^{1}$ O temor da propagação de infecção foi também responsável pelas barreiras físicas observadas entre os leitos individuais nos hospitais pediátricos mais antigos e pela separação física das divisões obstétrica e pediátrica nos grandes hospitais gerais. Como resultado, as maternidades passaram a reunir os bebês em grandes berçários, num arranjo semelhante a uma fortaleza, estabelecendo os germes como os seus grandes inimigos. Portanto, os pais e outros familiares, considerados seus portadores, eram mantidos afastados.

Segundo Rodriguez (1998), concordando com Knobel (1998), o centro de tratamento intensivo (CTI), que teve sua origem na acentuada preocupação de isolar pacientes graves, transformou-se numa exigência dos hospitais modernos. Fruto do extraordinário avanço das ciências médicas e da tecnologia do século XX, tornou-se responsável pela recuperação de casos que apresentavam prognóstico sombrio ou fatal. Assim, transformou-se num lugar de equipamentos sofisticados, pessoal técnico extremamente qualificado, com atenção constante, exames e rotina, visando a manter a vida a todo custo, mas trazendo, com isso, um sem número de exigências ao paciente, à sua família e à própria equipe.

Nas unidades de tratamento intensivo neonatal, não foi diferente, apesar de, em seus primórdios, existir a idéia de que a separação do bebê e sua mãe não deveria ocorrer. $O$ primeiro texto de perinatologia foi escrito por Pierre Budin, em 1907. Esse autor observou que um certo número de mães abandonava os bebês que haviam permanecido isolados para os cuidados neonatais, pois não lhes era permitido estarem próximas e acompanharem o desenvolvimento ou a recuperação de seus filhos. Budin dizia que a vida do pequenino fora salva, mas às custas de acabar perdendo a mãe. Recomendou, então, que elas fossem encorajadas a amamentar os próprios bebês e até outros que tivessem nascido a termo, a fim de aumentar sua produção de leite. Idealizou e promoveu o uso de incubadoras com paredes de vidro, que permitiam que seus filhos pudessem ser observados. Em razão dessas mudanças, as mães passaram a ficar mais atentas às necessidades de seus recém-nascidos, mesmo quando estes permaneciam no hospital por um período de tempo prolongado. "Em todos os sentidos, dizia ele, é melhor colocar o pequenino em uma incubadora ao lado da cama de sua mãe; a supervisão que esta exerce não deve, jamais, ser subestimada" (Klaus \& Kennell, 1993, p. 170). Tais considerações, porém, foram desconsideradas, e, por muito tempo, houve restrições quanto à proximidade família-bebê.

Atualmente, as UTIs neonatais caracterizam-se por receber pacientes na faixa etária de zero a dois meses de idade, nascidos pelo menos a partir da $23^{a}$ semana de gestação. Em sua maioria, as internações são feitas imediatamente após o parto, sendo menor o número de internações de pacientes que passaram um pequeno período em casa. Segundo Druon (1999b), "a qualidade da sobrevivência do bebê geralmente depende dos primeiros instantes: com alguns minutos de vida, logo que chega ao centro de medicina neonatal, o bebê é monitorado e, quando necessário, colocado no respirador e depois instalado numa incubadora, pesado, medido e submetido a múltiplos exames" (Druon, 1999b, p.36). Portanto, a separação física bebê/família é imediata à saída do útero materno, configurando uma experiência de descontinuidade muito precoce para todos, seja bebê, seja família.

Numa UTI neonatal, a maior freqüência de internações deve-se ao nascimento pré-termo, ao desconforto respiratório e à ocorrência de asfixias, apesar de também serem presentes quadros de má formações ou síndromes genéticas. Os horários de visita da família, em geral, são mais extensos do que numa UTI de adulto, sendo permitida a permanência de alguns membros da família entre 12 e 24 horas por dia. Programas de atenção humanizada, como a metodologia canguru, cuidados nos manuseios e respeito ao nível de maturidade do bebê, vêm sendo implantados com muito sucesso e muito bons resultados. Tais programas pressupõem uma atenção especial ao momento evolutivo do bebê e às questões psíquicas que envolvem uma internação neonatal.

\section{A Reorganização Psíquica na Gestação}

Pensando áreas de atuação do psicólogo, é essencial lembrarmos que sua intervenção na família, que participa, com o bebê, do atendimento intensivo neonatal, se dá numa situação de crise (Morsch, 1990). Além da internação do bebê, permeada por ansiedade em função da proximidade com a ameaça de morte ou de seqüelas, a família vinha experimentando um período de funcionamento psíquico especial que precede a chegada de um novo membro. Intervir, portanto, nesse momento, pressupõe o conhecimento dos aspectos próprios do período,
1 Lembramos certa mãe relatando que, ao se encontrar. residindo em outro país da América Latina, seu bebê de aproximadamente um ano necessitou de internação em UTI pediátrica. As visitas, mesmo dos pais, eram proibidas. Sua única possibilidade residia em entregar as fraldas que seriam colocadas em seu bebê. Assim, ela passou a escrever nas mesmas tudo o que gostaria de dizer para seu filho, garantindo, dessa forma, extremamente criativa, o contato $e$ a comunicação com seu bebê, apesar da distância que era obrigada a respeitar (relato pessoal). 
especialmente os relativos à mulher grávida, que traz consigo demandas únicas e pontuais, além da compreensão da experiência familiar quando da internação de um bebê.

Segundo Stern (1997), com a descoberta da gravidez, inicia-se, para a mulher, um período de reorganização psíquica que determinará, próximo ao nascimento, uma série de tendências de ações, de sensibilidade, de medos, de fantasias e de desejos, que ele denominou "Constelação da Maternidade". Preocupações importantes quanto à capacidade de gerar um filho saudável e perfeito, proporcionar crescimento e desenvolvimento físico ao seu bebê, assim como sua competência de promover o desenvolvimento psico-afetivo do filho, fazem parte das questões que invadem a mulher nesse momento. Por outro lado, a futura mãe sabe que, para cuidar de seu bebê, irá necessitar de apoio familiar e/ou da comunidade, o que a faz buscar uma rede de apoio que forneça atenção para ela e para o bebê. Junto a isso, existe uma grande preocupação com sua própria inserção social e seus aspectos individuais como mulher e como pessoa, levando-a a um intenso trabalho psíquico em relação à reorganização de sua identidade após a chegada do bebê.

Ainda segundo Stern (op.cit), à medida que o feto cresce no útero materno, a mãe desenvolve representações mentais acerca do bebê que está gerando. Essas representações são responsáveis pelo imenso trabalho de construção do bebê, do ponto de vista biológico e psíquico, participando da formação do bebê, que foi chamado por Lebovici (1991) de imaginado, precedido pelo bebê fantasmático e pelo bebê imaginário. $\mathrm{O}$ primeiro deles - fantasmático, teve seu início quando a mãe era um bebê, sujeita aos cuidados maternos. Foi-se estabelecendo em sua infância, nas brincadeiras que realizava com suas bonecas, prosseguindo durante a adolescência através das fantasias de ser mãe. Já o bebê imaginário teve início quando ela percebeu-se grávida , mesmo que não conscientemente, povoando suas fantasias pela nova pessoa que surgia em seu corpo. Sua configuração biológica, seus movimentos, os registros ultrassonográficos, foram permitindo novas representações, originando o bebê imaginado, pensado conjuntamente pelos pais, irmãos e avós, de acordo com sentimentos e representações que ele, objetivamente, provocou nos mesmos.

É no final do segundo trimestre e início do terceiro trimestre da gravidez que, de acordo com Klaus \& Kennel (op.cit.), a gestante já é capaz de especular sobre o tipo físico e o tipo de personalidade de seu bebê, pois a imagem do bebê imaginário em seu psiquismo encontra-se no auge. Durante esse período, Stern diz que a mulher começa a considerá-lo um bebê vivo que logo será um indivíduo independente. Tal consciência pode ser observada através de um estado de prontidão para a chegada do bebê, incluindo vontade manifesta de que ele possa nascer logo.

Para que isso possa ocorrer, no final da gestação, a mulher entra num processo de anulação progressiva das representações relatadas acerca de seu bebê imaginário. As representações vão diminuindo, tornam-se menos ricas, menos específicas e menos delineadas. "Este movimento psíquico é decorrente de uma tentativa que a gestante faz de proteger intuitivamente seu bebê que está por vir, e a si mesma, de uma provável discordância entre o bebê real e o imaginário, o bebê representado de maneira bastante específica" (Stern, 1997, p.28). Ela, então, desfaz suas representações mais positivas acerca do bebê imaginário e imaginado, para evitar desapontamentos futuros. Tal processo torna-se fundamental, segundo o autor, para que a mãe e o bebê real possam estabelecer uma relação. Essa consciência prepara a mulher para o nascimento e para a separação física de seu filho, facilitando a elaboração da separação que irá ocorrer pelo nascimento.

\section{O Final da Gravidez e a Internação do Bebê na UTI Neonatal}

Para algumas mulheres, o nascimento do bebê não coincide com o que elas esperavam como finalização de sua gestação. Ao ser constatado que o bebê apresenta problemas ainda dentro do útero, torna-se necessária a interrupção da gestação para a segurança de ambos, mãe e filho, ou então pode ocorrer o parto prematuro espontâneo. Na ocasião, a família, que não está preparada para enfrentar tal situação, vê-se imersa em emoções angustiantes. Tais sentimentos também se apresentam quando o bebê, apesar de nascer a termo, precisa de cuidados e vigilância imediatos por ter apresentado alguma insuficiência ou patologia. Em ambos os casos, a transferência desses recém-nascidos para unidades de tratamento intensivo é necessária por um período mínimo de 48 horas. Temos, então, o bebê retirado da presença da mãe logo após o parto e levado para a UTI neonatal, dificultando o encontro entre ele e toda a família.

Numa UTI neonatal, os bebês são observados permanentemente. A cor da pele, a reatividade, os parâmetros cardíacos e respiratórios são observados dia e noite pela equipe, e, ao mínimo sinal de complicações, ocorrem intervenções médicas ou 
de enfermagem, visando a melhores condições para o bebê.

A mãe que acabou de ter o bebê encaminhado à UTI pode sentir-se inteiramente dominada por um sentimento de incapacidade e de culpa. Todas as suas referências de maternagem e cuidados com o bebê parecem não fazer sentido. E mais - no nascimento prematuro, ela não pode viver psiquicamente as questões próprias do final da gestação que a conduziriam ao desempenho das novas tarefas. Portanto, faltam-lhe algumas peças do incrível jogo de relações que se iniciaram ainda intra-útero, e que precisam ter continuidade nos primeiros contatos com o bebê, fora de seu corpo. Afinal, o que se espera após o nascimento de um bebê é que ele vá diretamente para os braços da mãe, saudável e capacitado a entrar em comunicação, em trocas interativas. Mathelin, assim como Druon (1999b), destaca que a angústia relacionada ao presente e ao bebê vem acompanhada da culpabilidade das mães, que acreditam terem colaborado para o nascimento de risco através de seus pensamentos ou desejos inconscientes ou conscientes.

Para Agman, Druon e Frichet (1999a), geralmente, o pai ocupa-se primeiramente da criança na UTI, pois a mãe não se encontra em condições físicas devido à recuperação que necessita fazer após o parto. O pai, então, é o primeiro a ter contato com o serviço de terapia intensiva, sendo informado pela equipe sobre as primeiras avaliações do bebê e os procedimentos iniciais de seu cuidado. A entrada em um serviço hospitalar, em alguns casos, pela primeira vez, pode levar a uma fragilidade do pai ou ao surgimento de formações reativas do mesmo. Muitas vezes, observamos seu imenso esforço para fazer frente a sentimentos ambivalentes em relação à esposa, enquanto se identifica com esse bebê inacabado, que the parece um pouco "maltratado" e em sofrimento desde que nasceu. Por outro lado, preocupa-se em como transmitir à companheira, de forma clara, mas muito esperançosa, as primeiras notícias sobre o bebê. Da mesma maneira que a mulher, o pai deve suportar a ferida narcísica que o bebê ocasiona, pois trata-se de uma produção que também é sua e que não foi levada a um bom final. Assim como o bebê, que não estava preparado para nascer, e, por isso, precisa dos cuidados intensivos, o pai, e também a mãe, ainda não estavam preparados para assumirem seus papéis, caracterizando o que Mathelin denominou de prematuramente mãe e pai.

De acordo com as observações que realizamos, a entrada do pai no serviço possibilita o estabelecimento de um vínculo muito especial entre ele e o filho. Em nascimentos a termo, a mãe assume o papel de apresentar e de dar os cuidados mais essenciais ao bebê. Já na situação de internação, o pai é o primeiro a interagir, a descobrir as particularidades do filho recém-nascido. Assume o papel de apresentar o bebê à mãe, cuidando do que for necessário enquanto esta não puder estar presente, como, por exemplo, ficar atento para que o bebê não fique sem fraldas ou que tenha sempre mudas de roupas limpas em sua incubadora.

A partir de entrevistas feitas com pais de bebês internados em UTI neonatal, Agman, Druon e Frichet (1999a) descrevem as fantasias das mães nesse período específico. A maior dificuldade relatada é que ela teme não se sentir mãe enquanto o bebê está no serviço de neonatologia. Em outro estudo, Druon (1999b) relata entrevistas realizadas com o pai e a mãe, onde descreve que não só a mãe, mas também o pai, têm dificuldades em assumir seu papel. Entre tais dificuldades, as mais evidentes, segundo a autora, são: o dever de sentirem-se pais de uma criança doente, que foi investida no tempo da gravidez, mas que eles ainda não deveriam estar conhecendo; não poderem carregar os filhos enquanto estranhos tocam neles; a necessidade de vestirem trajes esterilizados semelhantes aos dos profissionais, e, ainda, o dever de investir no bebê tal como ele é, sem, entretanto levar muito longe esse investimento, para se protegerem de um luto muito cruel, se ele vier a falecer. "Em certos casos, o serviço é vivido como uma mãe toda poderosa, que arranca o bebê dessa mãe indigna que não pode terminar sua obra. $\hat{E}$ vivido como um juiz dessa incapacidade e, ao mesmo tempo, como único recurso para a sobrevivência do bebê" (Druon, 1999b, p. 40).

O serviço representa uma "interdição" do contato entre mãe e bebê. O recém-nascido está nas mãos de um serviço médico; outras mulheres estão lá para lembrá-la que ela não concluiu o seu trabalho e que, por isso, não poderá viver um contato tão íntimo com o bebê, como teria feito nos primeiros dias na maternidade ou em casa. "Os presentes estão suspensos... As felicitações interrompidas. Só restam a angústia e as cobranças implícitas. A mãe e seu bebê não estarão jamais a sós. Há o bebê vizinho, o pessoal que passa e se ocupa de suas atividades, em suma, ela não pode se envolver completamente com seu bebê" (Agman, Druon \& Frichet, 1999a, p. 27).

Ainda segundo os autores, a mãe assume um papel de cuidadora daquele bebê que é designado como seu, mas que permanece sob os cuidados do serviço de neonatologia. Dessa forma, provavelmente, quando sair da maternidade com o bebê, depois da internação na UTI, tem maiores chances de ocupar uma função mais médica do que maternal. Portanto, o que se caracteriza no

\section{A mãe que acabou de ter o bebê encaminhado à UTI pode sentir-se inteiramente dominada por um sentimento de incapacidade e de culpa. Todas as suas referências de maternagem e cuidados com o bebê parecem não fazer sentido.}


momento da internação é um estado de preocupação médica primária, diferentemente daquele denominado por Winnicott como preocupação materna primária. O foco que ela pode dirigir aos cuidados com seu bebê está intimamente relacionado com o quadro clínico do bebê, com os resultados dos exames do bebê, com a sintomatologia que ele apresenta e a terapêutica que vem sendo utilizada.

\section{Diretrizes do Trabalho do Psicólogo com os Pais dos Bebês}

Procurando estabelecer pontes entre as colocações teóricas e a prática da assistência em cuidados intensivos neonatais, formulamos algumas propostas de trabalho. Temos, assim, como possibilidades de intervenção pelo serviço de Psicologia:

Colocar-se como ponto de referência para a família na UTI - fator fundamental em um ambiente que tem grande rotatividade de profissionais, todos necessariamente voltados, em primeira instância, para os aspectos de cuidado clínico com o bebê. Com isso, é possível desempenhar uma função de continuidade através de uma escuta diferenciada que privilegia uma visão mais integrada do bebê e de sua história. Ao mesmo tempo, permite aos pais investirem nos bebês, enquanto recebem apoio e amparo de um representante da equipe.

Ajudar os pais a falarem sobre esse nascimento diferente - para que eles possam organizar seus pensamentos, identificar seus sentimentos, visando a melhor entenderem a situação de internação, o que irá facilitar a interação com o bebê.

Ajudar na comunicação pais/bebê -facilitar o diálogo afetivo com o bebê, estimulando a leitura das expressões, das condutas dos bebês nas particularidades de seus gestos e suas respostas quando em comunicação ou proximidade com os pais.

Ajudar a mãe a olhar o bebê como um outro, e não como parte integrante de si - movimento fundamental para que ela possa investi-lo como sujeito. O reconhecimento da separação pelo parto e pela internação implica o reconhecimento da história desse bebê. Ao mesmo tempo, cria um espaço para que ele se torne um indivíduo.

Oferecer aos pais dos pais participação na atenção e cuidado da família no período de internação do bebê - estimular a presença dos avós durante a internação, na medida em que, nesse período, a atualização dos vínculos familiares e a evocação dos cuidados recebidos em suas infâncias são fundamentais para que eles possam assumir seus papéis de pais e inserir o bebê na trama familiar (Braga, 2001). Mais do que participar dos cuidados com o neto recém-nascido, devemos incentivar os avós a colocarem-se à disposição para oferecer o holding do holding, através dos cuidados com os próprios filhos, pais dos bebês.

Ajudar na comunicação pais/equipe - tem como objetivo estabelecer uma ponte entre pais e profissionais. Os pais, muito comumente, apresentam sentimentos ambivalentes em relação à equipe, pois, ao mesmo tempo em que se sentem expropriados de seus bebês, têm consciência de que eles se dedicam a cuidá-los através de toda uma tecnologia e um conhecimento muito especial. Assim, os profissionais são alvo de projeções intensas da família do bebê, o que facilmente desencadeia conflitos na relação. Bowlby (1979) cita Wenner, que diz: "uma mulher que passa por sérias dificuldades emocionais durante a gravidez e o puerpério tem, comprovadamente, dificuldades em confiar em outras pessoas. Ela é incapaz de expressar seu desejo de apoio ou então o expressa de um modo agressivamente exigente, refletindo num caso ou outro sua falta de confiança em que esse apoio the será dado" (Bowlby, 1979, p.99). Sem dúvida, tal fato representa a fragilidade de uma relação que se dá de forma emergencial e urgente, sem um preparo ou uma escolha anterior. A equipe invade a história do bebê e de sua família, premida pelas necessidades clínicas do bebê e por um desejo imenso de desempenhar sua função.

Atendimento aos pais dos bebês - tem o objetivo de atender às diferentes demandas dos casais. Pode ser realizado através de reuniões de pais ou ainda junto à dupla parental ou apenas a um dos pais dos bebês, no interior da UTI, ou numa sala reservada para isso. Permanecer com eles, numa visita ao bebê, fazendo pequenas observações sobre o encontro, faz com que eles mesmos encontrem formas de aproximação com o filho e possam, dessa forma, descobrir seus sentimentos, suas dúvidas, verbalizálos e discuti-los com alguém da equipe.

Trabalhar as possíveis perdas ocorridas na UTIperdas que podem ser reais, como a morte ou o risco de seqüelas no futuro desenvolvimento da criança - as perdas ocorridas no imaginário familiar, relacionadas ao bebê imaginário ou ainda à falta de privacidade e intimidade da mãe com seu bebê. No caso de a possibilidade da morte do bebê ser reconhecida pela equipe, o trabalho de aproximação de toda a família com o bebê é extremamente recomendado e deve ser prioridade para o psicólogo. 


\section{As Implicações da Chegada de um novo Bebê para os Filhos mais Velhos do Casal}

De acordo com Klaus \& Kennell (1993), para algumas crianças, a experiência de ter e se tornar um irmão está entre as mais estressantes do início da infância. Com a chegada de um novo bebê, tanto as rotinas familiares quanto os relacionamentos começam a tomar dimensões inesperadas. Os autores revelam que as reações mais comuns, ao nascimento de um irmão ou uma irmã, incluem agressão ou hostilidade para com o bebê ou a mãe, regressão e esforços aumentados para chamar atenção. Também é observado, em algumas crianças, surtos de desenvolvimento de domínio ou independência, uma vez que tenham se tornado irmão ou irmã mais velhos.

Dessa forma, o nascimento de uma irmã ou um irmão introduz um grande número de mudanças. As alterações nas rotinas e interações familiares começam antes mesmo da chegada do bebê. Durante a gravidez, o corpo da mãe altera-se, bem como seu humor e nível de energia.Quanto melhor os pais puderem lidar com os conflitos e pressões impostos pela instalação dessa nova situação, melhor poderão ajudar os primeiros filhos a se tornarem e a terem irmãos. Baseados em diferentes estudos, Klaus e Kennell (op.cit.) ressaltam a importância do papel do pai, na experiência do filho mais velho, especialmente se a mãe tem o bebê em um hospital e precisa ficar internada alguns dias. Afirmam que o envolvimento anterior e atual do pai, na vida do filho mais velho, parece correlacionar-se diretamente com o nível de adaptação conseguido pela criança face à separação temporária da mãe e ao grau de aceitação demonstrado para com o novo irmão. Se a mãe está fisicamente ausente e emocionalmente distante, depois do nascimento do bebê, o pai pode proporcionar uma continuidade na vida emocional dos outros filhos.

Portanto, adaptar-se ao nascimento de um irmão saudável, nascido a termo, ainda se caracteriza como uma experiência extremamente difícil para as crianças. Já o nascimento de um bebê prematuro ou com um sério problema transforma a feliz expectativa de todos em tristeza e preocupação. As crianças têm consciência e percebem que algo está errado, mas sabem, apenas de forma superficial, do que se trata. A atenção dos pais é diminuída, já que se encontram totalmente preocupados com os próprios sentimentos de pesar em relação ao bebê internado. O tempo que os pais dispõem para os demais filhos tornase reduzido devido às freqüentes visitas ao hospital, recados inesperados e chamadas telefônicas advindas de parentes e amigos preocupados. Muitas vezes, os pais fazem um extremo esforço para encontrarem horários extras para os demais filhos, mas o que nos relatam é que seus pensamentos permanecem ao lado da incubadora, próximos ao bebê, na UTI neonatal, o que leva os demais filhos a experimentarem sua presença apenas física, sem a atenção e a disponibilidade psíquica que necessitariam no momento.

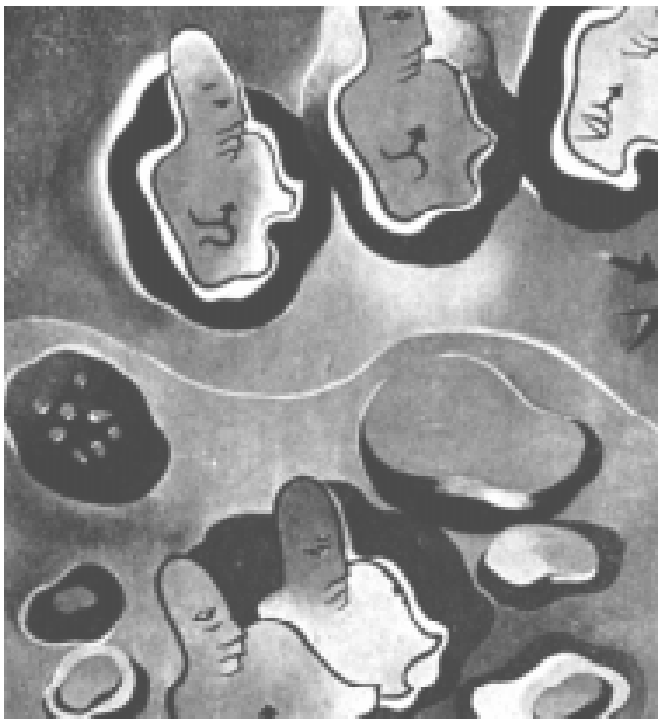

A atenção dos pais é diminuída, já que se encontram totalmente preocupados com os próprios sentimentos de pesar em relação ao bebê internado.
Outro aspecto importante é que, durante o período de crise que se instala com a internação do bebê na UTI, os pais tendem, num primeiro impulso, a proteger suas crianças das tristezas e confusões pertinentes à situação mandando-os para longe de casa, junto a parentes e amigos. Acreditam que o ambiente estável de outras famílias será melhor do que o seu próprio, que se encontra imprevisível. Porém, a experiência tem demonstrado que essa atitude não ajuda as crianças a lidar com as dificuldades associadas ao nascimento de um bebê pequeno demais ou doente. As crianças saem-se melhor quando continuam a fazer parte da rotina doméstica e experimentam a nova situação familiar junto aos pais.

Segundo Klaus e Kennell, isso decorre de diversos fatores: primeiramente, deve-se ao fato de que as crianças tendem a ficar angustiadas por terem sido separadas dos pais. A angústia intensifica-se quando a separação ocorre de forma inesperada e cercada por uma aura de emergência.

Em segundo lugar, a maior parte das crianças sofre mais com suas fantasias acerca do que saiu errado do que com a experiência direta, com o problema real. O afastamento da família pode invocar fantasias bem mais amedrontadoras do que a realidade. Além disso, longe de casa, as crianças 
têm poucas oportunidades de corrigir suas fantasias e poucos adultos de confiança com quem compartilhar suas preocupações.

Em terceiro lugar, ressaltam que as crianças necessitam da garantia dos seus pais de que não são as responsáveis pelos problemas do bebê. O sentimento de culpa decorrente da ambivalência que as crianças possam ter tido quanto à chegada do bebê, durante a gestação, são muito freqüentes. Em geral, apresentam reações ambivalentes e negativas à perspectiva da chegada de um novo membro na família. Algumas vezes, desejam, inclusive, que os bebês nunca apareçam. Assim, podem interpretar tais sentimentos como os causadores dos problemas do bebê, razão suficiente para sentirem-se culpadas. De acordo com esse contexto, ser mandado para longe de casa pode ser interpretado como uma punição pelos maus desejos. É importante, ainda, que os pais tentem discutir o que está acontecendo, o motivo da internação do bebê e como eles estão se sentindo frente à situação.

\section{Diretrizes do Psicólogo para com os Irmãos dos Bebês em UTI Neonatal}

Ajudar os pais a encontrar modos de reunir esforços para estarem disponíveis para os outros filhos, apesar da situação de crise em que se encontram.

Promover visitas supervisionadas dos irmãos dos bebês, com o objetivo de:

Ajudar a esclarecer o que está acontecendo com o bebê, o motivo da internação e as necessidades que ele vem apresentando.

Ajudar na compreensão de onde está o bebê e incentivar sua participação na experiência familiar, reforçando seu lugar no grupo familiar.

Fornecer explicações apropriadas à idade sobre as complexidades da UTI - através de atividades lúdicas supervisionadas, com o uso de bonecas e materiais utilizados no cuidado dos bebês, como seringas, sondas, gazes, entre outros (Morsch, 1997).

Organizar a experiência da criança - ocorrida no decorrer da visita, com uma conversa posterior, incentivando a mesma a falar de seus pensamentos, sentimentos e impressões a partir da entrada na UTI. Novamente, é recomendada a utilização da expressão gráfica ou lúdica pela criança.

Facilitar o desenvolvimento do vínculo irmão/ bebê - durante a internação, para torná-lo um bebê real para a criança através de desenhos feitos em casa ou ao longo da atividade supervisionada, ou pelo incentivo de trazer um brinquedo ou bilhete que pode ser colocado no interior da incubadora do bebê. Ao entrar na UTI neonatal com um objeto que ela mesma produziu ou que ela escolheu para oferecer ao bebê, a criança sente-se mais segura para estabelecer os contatos iniciais com aquele que vem provocando tantas preocupações e alterações na rotina familiar e que, muitas vezes, o faz sentir desconforto.

Ajudar na elaboração do sentimento de culpa dos filhos mais velhos - a partir do momento em que a equipe que cuida do bebê estimula a proximidade, o contato com os irmãos, está garantindo que não os avaliam como causadores da doença do bebê. Assim sendo, os especialistas absolvem-nos de qualquer atitude ou pensamento que porventura tivessem, de serem a causa da internação do bebê. Ao mesmo tempo, o contato com os irmãos de outros bebês, visto encontraremse num mesmo horário para a visita, conversarem sobre o que está acontecendo, serve-/hes de alento, pois dão-se conta de que não são os únicos a viverem tal sofrimento.

\section{Considerações Finais}

Como apresentamos até aqui, é da maior importância facilitar a proximidade, comunicação e contato entre o bebê que se encontra sendo cuidado na UTI neonatal e sua família. Tratandose, como apontamos anteriormente, de uma situação de risco para o desenvolvimento das relações afetivas, não podemos mais pensar os cuidados em UTI neonatal sem envolver o grupo familiar, o qual traz, para dentro do ambiente intensivo, sua história. Com isso, poderemos ajudar a tecer a trama que vai configurar e garantir ao bebê seu lugar na família e torná-lo sujeito da própria história. Podemos ampliar ainda mais nossas sugestões e configurá-las numa proposta acerca da importância de oferecermos "holding" à família de bebês internados em um serviço de UTI neonatal, o que permite a experiência de estarem sendo envolvidos por um ambiente inclusivo e facilitador nos contatos com o bebê. Através da proposta de oferecer um "holding" a toda a família, é possível resgatar a competência dos diferentes membros familiares em suas funções de cuidadores e propiciadores dos vínculos afetivos, fundamentais para o desenvolvimento do apego com o bebê que iniciou a vida de maneira diferente.

Acreditamos que isso ofereça aos pais e aos bebês formas novas de interagirem em função das muitas mudanças ocorridas em relação aos projetos e em relação aos manejos milenares nos cuidados dos bebês, que impregnam nossa mente. A leitura de 
expressões faciais, os sentimentos provocados pelo toque, pelos cheiros reconhecidos, que configuram o chamado processo interativo, podem ser retomados com o auxílio da equipe. Marcado por olhares, pelo ritmo dos contatos corporais e pela harmonia entre os movimentos maternos e paternos com aqueles que o bebê apresenta, seja dentro da incubadora, seja na posição canguru, seja no colo, é a interação que vai ocorrendo e permitindo que os traços comuns sejam descobertos, e a familiaridade, a filiação e a maternagem e a paternidade se estabeleçam para permitir o surgimento do vínculo afetivo.

Pensamos que, assim, poderemos ajudar no estabelecimento de uma interação capaz de gerar um apego estável e seguro. Para tanto, o pai necessita oferecer sustento à mãe, apoiá-la quando ela estiver com o bebê nos braços ou na imaginação. Ao mesmo tempo, ambos devem ser ajudados pela equipe e pelo ambiente intensivo neonatal a oferecerem um significado para as sensações que experimentam juntos, próximos ao bebê, ou seja, cabe ao ambiente da UTI neonatal oferecer um colo para que a tríade possa embalar seus sonhos e continuar construindo sua rede de relações afetivas.

A proposta de oferecer holding e ser continente das angústias relativas ao contexto de internação poderá permitir que a família crie pontos de referências novos nessa história estranha, que não possui representações anteriores. Dessa forma, poderemos estar certos de estarmos contribuindo para a diminuição da angústia frente à situação de crise em que a família se encontra, ao mesmo tempo em que ela, por sentir-se menos ameaçada, poderá desempenhar papel mais ativo no significado do contexto de internação, nos vínculos familiares pré-existentes e nos que ainda estão por surgir.
Luciana Valansi \&

Denise Streit Morsch

Rua Gal Góis Monteiro no8, bl. G/1504 Botafogo-RJ. Cep: 22290-080. Tel: (21)2541-0731.

E-mail:Ivalansi@ms.microlink.com.br
AGMAN, M.; DRUON, C. \& FRICHET, A. Intervenções Psicológicas em Neonatologia In Agora Eu Era o Rei - os Entraves da Prematuridade. Salvador: Ágalma, 1999a.

BOWLBY, J. Formação e Rompimento dos Laços Afetivos. São Paulo: Martins Fontes, 1979.

BRAGA, N.de A., MORSCH, D.S., CARVALHO, M. \& LOPES, I.M Maternagem Ampliada - a Transgeracionalidade em UTI Neonatal. In Pediatria Moderna, vol. XXXVII, 2001, pp.312-317.

DRUON, C. Ajuda ao Bebêe aos seus Pais em Terapia Intensiva Neonatal In Agora Eu Era o Rei - os Entraves da Prematuridade. Salvador: Ágalma.

KLAUS, M. \& KENNELL, J. Pais/Bebê - a Formação do Apego. Porto Alegre: Artes Médicas, 1993.

KNOBEL, E. Condutas no Paciente Grave. São Paulo: Ed. Atheneu, $2^{\text {a }}$ edição, 1998.

LEBOVICI, S.; LAMOUR, M. Les Interactions de Nourisson avec ses Partenaires: Évaluation et Modes d'Abord Préventifs et Thérapeutiques, In La Psychiatrie de I'Enfant, vol. XXXIV, fasc.1, 1991, pp.171-275.
MATHELIN, C. O Sorriso da Gioconda - Clínica Psicanalítica com os Bebês Prematuros. Rio de Janeiro: Companhia de Freud, 1999.

MORSCH, D.S. A Situação de Alto Risco Neonatal. Dissertação de Mestrado. PUC-RJ. Rio de Janeiro, 1990

MORSCH, D.S., CARVALHO, M. \& LOPES, J.M. Programa de Acompanhamento e Visitação aos Irmãos de Bebês Internados em UTI Neonatal. In Pediatria Moderna, vol.XXXIII, 1997, pp. 481-487.

RODRIGUEZ, A. S. Abordagem Psicológica em uma Unidade de Terapia Intensiva. In Revista do Hospital de São Francisco da Penitência. RJ: julho/dezembro-1998.

STERN, D. A Constelação da Maternidade - o Panorama da Psicoterapia Pais/Bebê. Porto Alegre: Artes Médicas, 1997.

WINNICOT, D. Da Pediatria à Psicanálise - Textos Selecionados. Rio de Janeiro: Francisco Alves, 1982.
Referências 